\section{DEL ENSAYO LITERARIO AL ENSAYO AUDIOVISUAL: CORRESPONDENCIAS $Y$ ESTRATEGIAS}

\author{
Isleny Cruz Carvajal \\ Universidad Rey Juan Carlos \\ Universidad Complutense de Madrid \\ http://orcid.org/0000-0001-5959-629X \\ isleny.cruz.carvajal@urjc.es
}

Cómo citar este artículo/Citation: Cruz Carvajal, Isleny (2021). Del ensayo literario al ensayo audiovisual: correspondencias y estrategias. Arbor, 197(801): a611. http://doi.og/10.3989/ arbor.2021.801001

Recibido: 8 diciembre 2020. Aceptado: 12 febrero 2021. Publi-cado: 9 diciembre 2021.

RESUMEN: Este artículo refleja el estado de la cuestión de las correspondencias conceptuales, formales, lingüísticas y sociopolíticas del ensayo fílmico / audiovisual respecto a los cánones del ensayo literario. Resume los aportes teóricos esenciales en ambos campos. La exploración descifra cómo unos patrones de base permanecen idénticos por compartir una misma raíz en la experiencia reflexionada por el sujeto, pero su traslación al medio audiovisual, aun manteniendo una indudable convivencia de equivalencias, da cuenta de diferencias lingüísticas relativas a las propiedades de un dispositivo complejo, también determinantes para la evidencia mayor o menor de unos rasgos dados. Aunque las nuevas tecnologías ponen en alza la manifestación de la subjetividad, faltan estudios orientados hacia la incidencia de estas sobre la construcción del texto ensayístico y sus efectos sociales. Como efecto de este vacío, las referencias canónicas para analizar las correspondencias entre ambas manifestaciones no parecen contemplar experiencias de cinematografías periféricas ni profundizar en prácticas experimentales que dieran respuesta a lo anterior.

PALABRAS CLAVE: Ensayo audiovisual; ensayo literario; cine conceptual; lenguaje audiovisual; método experimental.

\section{FROM LITERARY ESSAY TO FILM ESSAY: RELATIONSHIPS AND STRATEGIES}

Copyright: (C 2021 CSIC. Este es un artículo de acceso abierto distribuido bajo los términos de la licencia de uso y distribución Creative Commons Reconocimiento 4.0 Internacional (CC BY 4.0).

ABSTRACT: This article reflects the state of the art of the conceptual, formal, linguistic and sociopolitical correspondences of the filmic / audiovisual essay with respect to the canons of the literary essay. It summarizes the essential theoretical contributions in both fields. The exploration deciphers how some basic patterns remain identical as they share the same root in the experience reflected by the subject, but their translation to the audiovisual medium, while maintaining an undeniable coexistence of equivalences, accounts for linguistic differences related to the properties of a complex device, which is also decisive for a greater or lesser demonstration of some given traits. Although new technologies raise the value of the manifestation of subjectivity, there is a lack of studies oriented towards their influence on the construction of the essay text and its social effects. As a result of this gap, the canonical references to analyze the relationships between both manifestations appear to not contemplate experiences of peripheral cinematographies or to delve more deeply into experimental practices that would provide an answer to the above.

KEYWORDS: Film essay; literary essay; conceptual cinema; audiovisual language; experimental method. 


\section{INTRODUCCIÓN}

El prólogo de Itinerarios y formas del ensayo audiovisual, la compilación más reciente en torno a la materia, destaca la enorme variedad de temas y expresiones por donde actualmente transita esta forma de expresión. Subraya una capacidad adaptativa a los distintos formatos y canales de difusión que lo convierte en "un terreno fértil para el encuentro y el descubrimiento de otras realidades y formas de reflexionar que aportan riqueza y diversidad a la cultura audiovisual» (Mínguez, 2019: 10-11). Desde una perspectiva más histórica y sociológica, otros autores ponen de relieve la dificultad de separar el ensayo de la problemática del sujeto en nuestra cultura, considerando su práctica fílmica como «un laboratorio donde pueden examinarse los resultados de la confluencia contemporánea de distintas formas de saber: literario, filosófico, artístico, emocional, tecnológico, psicológico, científico, etc., así como de diferentes modos de exposición de las mismas» (Català Domènech, 2014: 16). Y esta puede considerarse una analogía de primer orden respecto al papel transformador que en el Renacimiento cumplió el ensayo literario a partir de la obra de Michel de Montaigne.

Aunque la reflexión a través del lenguaje propio del cine se remonta a los hallazgos de la Escuela soviética y pasa por múltiples intentos a lo largo de varias décadas del siglo $X X$, el ensayo audiovisual -aquí sinónimo de ensayo fílmico- empieza su verdadera andadura hacia la década de los ochenta, estimulado por la adopción del vídeo (García Roldán, 2020: 108). Y si bien no deja de ser hasta el momento una práctica indefinible y un concepto problemático (Weinrichter, 2007: 23) que madura al margen de los modelos institucionalizados por las industrias televisiva y cinematográfica, a su imparable crecimiento contribuye una flexibilidad tecnológica de la que surgen experiencias y prácticas experimentales cada vez más autónomas, diversas y extendidas, definitorias para entender el papel que juega como clave notable de la comunicación social y audiovisual en estas primeras décadas del siglo XXI.

\section{VIDA, SUJETO Y FORMA}

Para identificar los principios del ensayo se seleccionan aquí dos categorías de autores: filósofos de base que a su vez son la referencia de filólogos especialistas en géneros literarios y, dentro de estos, en ensayo. Está menos sistematizada la información sobre el ensayo fílmico, debido a que este aún es un territorio reciente de experimentación, como en su momento y durante algunos siglos lo fue el ensayo literario. No obstante, es posible identificar sus conceptos y progresiva configuración mediante investigadores situados entre la historia y el análisis del cine.

«Por encima de la consabida dificultad para definirlo y situarlo, el texto ensayístico garantiza unas coordenadas inequívocas, descifradas desde los postulados de Lukács (1910), Bense (1947) y Adorno (1962), hasta unos delineamientos muy precisos localizados en la teoría de los géneros literarios y en las aproximaciones teóricas sobre el ensayo fílmico. Estas últimas cuentan con estudios ya clásicos desde finales del siglo XX, como el de Lopate (1996) y los consiguientes de Liandrat-Guigues (2004), Moure (2004), García Martínez (2006), Machado (2007), Montero (2006), Català (2014) y Mínguez (2019), entre muchos otros autores cuyas investigaciones profundizan en relaciones heredadas y en particularidades dispuestas por el mecanismo audiovisual» (Cruz Carvajal, 2019: 89).

El punto de referencia del ensayo es el objeto, la realidad, es decir, algo ya ocurrido (Lukács, 1910/2006). El principio de su contenido es la vida experimentada por el ensayista. La experiencia de esta vida implica el principio de verdad, lo cual hace que los textos ensayísticos se sitúen entre la intuición y la ciencia. Parte de la definición del ensayo, en su sentido de «intento", implica especialmente el acto de escribir en relación con el objeto de escritura, es decir, la interacción entre el sujeto y la realidad sobre la que escribe (Bense, 1947). Un fundamento más es que el ensayo somete a mediación la experiencia espiritual «como forma refleja mediante su propia organización conceptual», de lo que resulta un procedimiento ametódico que produce organizaciones únicas en su interior y que hace que se sostenga en las significaciones del lenguaje, siendo él mismo lenguaje. A falta de definición conceptual, se refuerza entonces su forma expositiva: lo que le falta de científico se contrapesa en la manifestación resultante de la fidelidad al proceso del autor: el contenido es la forma expresándose (Adorno, 1962: 23).

Si partimos de aquel principio benseniano según el cual el ensayo surge del carácter crítico de nuestro espíritu, resulta natural que sus antecedentes se remonten por lo menos hasta el nacimiento de la cultura occidental. Y también resulta natural encontrarlo no solo como forma literaria, sino también como posible manifestación en todas las artes (Liandrat-Guigues, 2004: 7). Aunque provenga de las necesidades más 
profundas del espíritu humano, el ensayo literario habría de esperar su nacimiento hasta la crisis del pensamiento sistemático para dar paso a la expresión de la subjetividad. Es la experiencia individual la que también se erige como la manifestación más poderosa frente a la pluralidad e inconsistencia de la realidad: una realidad que, con los efectos de la industrialización, se experimenta cada vez de un modo más azaroso. De ahí que el ensayo resulte ser «un vehículo de comunicación especialmente adecuado para expresar el nuevo pensamiento antimetafísico y antisistemático de la postmodernidad» (Arenas Cruz, 1997: 79).

Pese a lo anterior, mientras otras prácticas literarias han sido sometidas a estudios y explicaciones en tratados y manuales, con el ensayo ha pasado lo contrario (Arenas Cruz, 1997: 99). El resultado es que sus rasgos como clase de textos se configuraron libremente en el ámbito de la comunicación literaria y no literaria. Con todo, sus características predominantes permiten identificarlo como una modalidad posible dentro de los géneros argumentativos, lo cual deja paso a la observación de unos rasgos y procedimientos muy concretos y útiles para establecer una base teórica sólida donde fundamentar el análisis de obras ensayísticas no solo literarias sino también fílmicas, audiovisuales y de otros medios de expresión.

Los ejes planteados en el apartado siguiente son la conclusión que, a modo de constantes, se desprende en mayor o en menor grado de los principios filosóficos que justifican la existencia del ensayo -vida, sujeto y forma- y de las especificidades de su ubicación en el entramado de los géneros argumentativos. Así, se toman como marco de referencia las propiedades puntuales del texto ensayístico (Arenas Cruz, 1997) ${ }^{1}$, de las que partimos para estudiar los medios -con algunas variaciones- que los homologan en el ensayo fílmico/audiovisual, basándonos en los autores que más y mejor describen sus correspondencias.

«Todas [las] características del ensayo literario pueden aplicarse una por una al ensayo fílmico, pero teniendo en cuenta que su grado de complejidad aumenta con la mudanza por la introducción del factor audiovisual, que expande las funciones retóricas del espacio lingüístico. Para comprender lo que supone desplazar al campo de la imagen y del sonido los dispositivos retóricos que conforman las particularidades del ensayo literario es necesario sumergirse primero en las interioridades de esos mecanismos textuales, teniendo presente, sin embargo, que éstos, una vez actúan en el nuevo ámbito, se transforman y dan lugar a nuevas formas de expresión» (Català Domènech, 2014: 15-16).

Paralelo a la dificultad de desentrañar algunas correspondencias no muy visibles o de encontrar un lugar equivalente a ciertos rasgos puntuales, el orden de estas equivalencias sigue el criterio de lo que sería un proceso creativo de escritura o realización ensayística -donde, en todo caso, resulta muy difícil separar partes por principio indisolubles- regido por la secuencia: experiencia de la realidad manifestada por un yo (autor) / de la que deriva una forma-pensamiento que dialoga con un tú (receptor) / e interviene finalmente en la conciencia social (realidad).

\section{CORRESPONDENCIAS Y ESTRATEGIAS}

\subsection{Experiencia de lo real}

Como queda planteado por Lukács en los principios filosóficos, el referente del ensayo es la experiencia. Es decir que su desencadenante siempre está «fuera del texto». Por eso suele decirse que un ensayo se escribe con ocasión de... Pero al tratarse de una experiencia, los contenidos de ese referente se someten al pensamiento del autor, con lo que se presentan en una situación argumentativa. «Esto quiere decir que el marco que habremos de tomar como referencia no es el de las cosas reales, sino un plano lingüístico o de representación cultural, dado que los objetos del referente se instalan en esquemas de pensamiento" (Arenas Cruz, 1997: 161). Se dice que un ensayo surge justamente cuando un autor ensaya pensar sobre un tema que le exige construir la realidad. Trasladado este principio al ensayo fílmico, lo que vemos sobre la pantalla, aunque se trate de segmentos muy reales, solo existe por el hecho de haber sido pensado por alguien (Bergala, 2000, citado por Weinrichter, 2007: 27).

Además de que, por encima de la referencialidad objetiva, la representación ensayística se centra en la experiencia reflexiva de lo real, su objetivo es extraer el sentido de la verdad sobre esa vivencia aunque para ello sea necesario el empleo de estrategias no necesariamente realistas.

«El ensayo fílmico es una modalidad del cine de lo real, a la que pueden incorporarse luego dispositivos

1 Tomamos como referencia principal para identificar las propiedades del ensayo el texto Hacia una teoría general del ensayo. Construcción del texto ensayístico (Arenas Cruz, 1997) por ser el estudio más completo sobre la materia. 
retóricos provenientes de la ficción o que pueden decantarse eventualmente hacia lo ficticio como estrategia del proceso especulativo en el que consiste el medio. Se trata de moldear estos elementos reales para extraer de ellos su verdad, su realidad, una verdad y una realidad que no se encuentran, sin embargo, fuera del dispositivo sino que son una consecuencia del mismo, del proceso hermenéutico puesto en marcha por él mismo» (Català Domènech, 2005: 144).

Con independencia de cuánta sea su proximidad factual, al trabajar con lo ya sido y con la experiencia del sujeto, el ensayo tiene una conexión histórica permanente. Su práctica en el cine nunca ha llegado a prescindir por completo de la historia y a menudo esta ha sido para él mucho más que un tema, al punto de producir una relación compleja entre la historicidad y el hecho fílmico (Liandrat-Guigues, 2008: 106). Sin embargo, las modalidades de ese vínculo son variadas. Pueden ir desde el recurso a los archivos y a los documentos o recuerdos de las «películas de testimonios» hasta las distintas formas de mirar o reconstruir la historia apelando a maneras más ficticias, poéticas o metafóricas.

Realidad e Historia forman parte de lo que algunos autores entienden como «experiencia pública» (Corrigan, 2011: 33). El ensayo parte de los contenidos de un entorno socio-cultural en un momento de la Historia y unas circunstancias, pero su sentido está en el filtro de una experiencia individual que en el proceso de representarse termina interviniendo en el mismo espacio del que partió, sobre todo como un registro o serie de registros que dan cuenta más de un yo social que en última instancia interconecta diferentes individuos y grupos sociales en las muchas dimensiones de la vida.

Que lo primero sea la experiencia como contenido, proceso y valor último de la justificación ensayística indica una hegemonía del sujeto en su representación, no solo por ser el vehículo de esta sino porque de su existencia y presencia deriva toda una construcción formal y lingüística solo en virtud de la cual es posible su comunión efectiva con el receptor y, por extensión, su capacidad para intervenir en la conciencia social.

\subsection{Manifestación del sujeto}

Mientras que para el ensayo literario la identificación del yo en el enunciador se convirtió en la primera señal que lo diferenciaba del estudio y del tratado, para el ensayo fílmico implicó tener una de sus raí- ces en el documental performativo. Pero tanto el uno como el otro empiezan por compartir el objetivo de descubrir lo que el autor/sujeto piensa sobre el tema que ha elegido, en un rastreo que intenta deshacer el nudo mental de sus pensamientos (Lopate, 1996: 244). En ambos casos la presencia del sujeto tiene muchas maneras de evidenciarse e interactuar con el receptor, si bien la exposición ante una cámara puede hacer que en el ensayo fílmico tienda a estar más diluida en otras formas de enunciación.

Existen unas condiciones del yo que vienen perfiladas en el ensayo literario como género argumentativo y pueden ser perfectamente transportables al e identificables en el ensayo fílmico. "La presencia del autor en el texto argumentativo se realiza desde dos planos: 1) a través del mensaje mismo, cuyos indicios lingüísticos nos revelan la actitud de quien lo emite [...] y 2) el de su propia personalidad, haciendo patentes sus cualidades morales e intelectuales» (Arenas Cruz, 1997: 381).

Tratándose del ensayo audiovisual, en la mayoría de los casos esta personificación del yo en sus distintos niveles y con sus correspondientes funciones encuentra como primer vehículo el uso de la voz en off-«capaz de argumentar sin autoritarismo pero sin reducirse al ámbito doméstico" (Weinrichter, 2007: 29), enriquecida con otros recursos sonoros y visuales que tienen la capacidad de apoyar o matizar la subjetividad y canalizarse con efectividad hacia el receptor.

"The use of voice in an essay film can be all these things -it can be contrapuntal or ironic or polemical, as well as a means to convey information. It is also, first and foremost, a privileged tool for the author's articulation of his or her thought (in conjunction with sound and image), and hence a prime location of the author's subjectivity, as well as the main channel of the enunciator's address to the spectator» (Rascaroli, 2009: 38).

Otra de las particularidades es que esa voz puede corresponderse con la presencia del propio autor, haciéndose a sí mismo en escena. Es el caso del Orson Welles de F for Fake (1974) y del Jean-Luc Godard de Histoire(s) de cinema (1988-1998), apareciendo ante la cámara en su proceso de trabajo, escritura o montaje, y con su propia voz en off. Así, el cine puede reforzar y personalizar mucho más una exposición conceptual que va y vuelve al yo continuamente: «EI enunciador máximo [...] aparece como tal, organizando un discurso que él mismo modela y conforma des- 
de su identidad, donde experimenta el pensamiento con su propia biografía y actividad artística» (García Martínez, 2006: 102).

No está de más recordar que el objetivo del ensayo fílmico es transmitir el pensamiento mediante estímulos visuales y sonoros. Esto significa que, aunque sus recursos más inmediatos para patentar al sujeto son su voz y su presencia, cuenta con otros medios -no necesariamente y sobre todo no literarios- para lograr este cometido. En términos de expresión audiovisual, es perfectamente posible un ensayo sin comentario discursivo. La exigencia de un comentario discusivo -como lo haría Lopate- estaría haciendo confundir ensayo con discurso verbal (deformación literaria), "y estamos olvidando que el cine puede crear discurso por sus propios medios que no excluyen pero tampoco se agotan en la palabra [...] Una película no necesita una voz en off literal para tener voz o, como se suele decir, una mirada [...]» (Weinrichter, 2007: 28).

En equivalencia con estos mecanismos, «this act of enunciation can also be signaled in various formal or technical ways, including editing and other representational manipulations of the image» (Corrigan, 2011: 30-31). Opciones estilísticas de tal naturaleza están al mismo tiempo inmersas en una estructura que también da cuenta del flujo reflexivo. Más allá de los actos del habla y de la evidencia autoral, el sujeto se trasluce en la organización formal y en todos los componentes que hacen posible una representación que, además y sin proponérselo, desafía y desestabiliza los sistemas lineales narrativos, referenciales y científicos.

\subsection{Reflexión en la forma}

Desde la perspectiva del concepto ensayístico, la forma es un proceso que conecta la reflexión subjetiva con los recursos del lenguaje en una construcción cuya apertura, junto con otros contendidos, interactúa directa o indirectamente con el espectador. En el sentido de esa estructuración, el ensayo parece corresponderse primordialmente con la noción de forma aristotélica (poética) como una organización/ coherencia interna -no sistemática- $y$, en un sentido simultáneo, con las figuras del lenguaje de las que también se nutre la primera, sin que su escritura se adapte a patrones externos de presentación de ideas como los de la retórica, la ciencia o la dialéctica propiamente dichas.

"La noción de forma/estructura no implica, por con-

siguiente, un modelo externo que rija la presentación de las partes, sino el proceso dinámico por el que los distintos fragmentos textuales quedan organizados buscando una cierta coherencia interna. La forma del texto no deriva de ningún esquema, plan o modelo ya dados, sino que es el resultado de un proceso de búsqueda, de una actividad en la que se articulan principios heterogéneos. Es menos una estructura que una estructuración» (Arenas Cruz, 1997: 318).

Por derivar de la misma evolución del pensamiento del autor, con sus interrupciones y asociaciones repentinas, la primera propiedad de la forma-ensayo es la asistematicidad, de la que surge una flexibilidad y espontaneidad que parecen simular la sucesión natural y discontinua de los pensamientos tal y como se presentan. Al reivindicar las oscilaciones del yo, el ensayo «dibuja un tablero de perspectivas múltiples en las que resulta tarea imposible la fijación definitiva, la unidad» (García Martínez, 2006: 90), oponiéndose así a un sistema de representación y planteando automáticamente una apertura que le permite aumentarse o continuarse según la disposición del sujeto y del tema en el que su pensamiento esté implicado: "La estructura de un ensayo es, si cabe, esencialmente funcional para poder así acomodar en su interior al yo del autor y el fragmentarismo propio del género» (García Martínez, 2006: 90).

Justo esa cualidad inevitablemente abierta e inacabada de la estructura ensayística se contrapesa con el privilegio del fragmento (instante) como efecto natural, siendo posible su traslación idéntica en el ensayo fílmico:

«Tanto la cualidad antisistemática del ensayo como la personalista privilegian una filosofía del instante, un pensamiento que se construye, con sus dudas y problemas, conforme avanza la propia obra. Los films-ensayo se mueven en tiempo presente-el tiempo en el que se elabora el discurso-, aunque puedan hacer digresiones históricas o personales al pasado o al futuro [...] Esta misma actualización hace del ensayo una estructura abierta, en espera de nuevas aportaciones del yo al tema u objeto pensado» (García Martínez, 2006: 95).

El supuesto caos de la digresión y el fragmentarismo como condiciones determinantes de la estructura ensayística transcribiendo el yo se nivela con la coherencia semántica, que no es tanto una lógica como una correspondencia interna, de manera que «podemos articular los dos aspectos contradictorios del problema de la forma/estructura del ensayo: su fragmenta- 
rismo o su tendencia digresiva, por un lado, y su unidad de sentido, por otro" (Arenas Cruz, 1997: 328). El principio unificador de la aparente dispersión es la argumentación, consistente en la voluntad de imprimir una orientación sobre aquello acerca de lo que el autor reflexiona.

Digresión y tema central tienen potencialmente igual relevancia, dado que en la primera está la mayor proyección del sujeto, de cuyo flujo mental depende que la estructura pueda tener distintos grados de dispersión o de orden. Los ensayos más marcados por la subjetividad e imprevisibilidad del pensamiento producirán formas aparentemente más desorganizadas, por encima de las cuales siempre habrá un hilo argumentativo dando coherencia a las ideas (Arenas Cruz, 1997: 333). Tanto en su arbitrariedad como en su posible lógica, estas propiedades se presentan con igual identidad en el ensayo fílmico o audiovisual, con la diferencia, respecto al ensayo literario, de que en el campo audiovisual es frecuente tomar como canon de representación la narración clásica y no tanto los modelos retóricos, científicos o dialécticos de las prosas literaria y doctrinal.

«Todos los elementos que entran en juego en el ensayo fílmico se articulan entre ellos por acumulación y yuxtaposición, no necesariamente de forma lógica. Aunque pueda contar con fragmentos narrativos en su interior, las películas ensayísticas no se rigen habitualmente por la causalidad narrativa sino por la fluencia del yo. Éste va deslizando sus impresiones sobre diversos conceptos que forman el cuerpo del ensayo $\sin$ un orden claramente predeterminado. Manteniéndose dentro de una unidad u orden global, el ensayo fílmico presenta una estructura aparentemente sinuosa y confusa en la que muchos de sus elementos se emparentan por relaciones espontáneas, retóricas, ideológicas o simbólicas. El montaje tiene la función de acoplar los heterogéneos segmentos que integran el ensayo, la multiplicidad de recursos y discursos que debilitan la noción de texto único: voz en off, fragmentos de representaciones ficticias, uso de la música, citas literarias y fílmicas, efectos sonoros, utilización de cuadros o diagramas, material de archivo, etc.» (García Martínez, 2006: 99).

En el ensayo audiovisual, por tanto, la integración estructural es un equivalente del proceso de montaje entendiéndolo como el conjunto de la forma -e incluso como un sinónimo de esta-, o como una técnica de yuxtaposición para ensamblar y crear significados específicos entre la fragmentación múltiple.

\subsection{Heterogeneidad y recursos disímiles}

La complejidad de la experiencia humana y sus distintas maneras de confrontar y expresar la realidad hacen que la intervención del sujeto en la representación acuda a una cantidad ingente de herencias genéricas, lingüísticas, materiales y estilísticas. El proceso de significación convierte al ensayista en un «combinador» tanto de lenguajes como de recursos (Bense, 1947). En consecuencia, la heterogeneidad y los recursos disímiles son contenidos inseparables de la estructura fragmentada que se articula con las digresiones del ensayista volcadas a través de

«[...] citas, impresiones personales o cavilaciones marginales, bosquejos de personas o de escenas, referencias autobiográficas o confidencias, dichos y sentencias, pequeñas narraciones, afirmaciones generales, argumentos, exposiciones y explicaciones, diálogos, etc., fragmentos que algunas veces parecen acoplarse con aparente desorden a lo largo de la argumentación. De ahí la hipótesis de que la estructura del ensayo es una especie de redecilla en la que siempre es posible añadir o quitar algún fragmento» (Arenas Cruz, 1997: 319).

La correspondencia de esta característica en el ensayo audiovisual es una de las que más se evidencian en su esfuerzo por visibilizar los conceptos, pensamientos e ideas mediante un repertorio de medios expresivos que superan el documental clásico (Richter, 2007: 188). Puesto que la finalidad del ensayo no es reproducir el exterior ni la cronología de los hechos, es posible la integración de material visual de variadas procedencias y una secuenciación espaciotemporal libre de la reproducción objetiva: «Se pueden representar cosas tanto muertas como vivas, tanto artificiales como naturales, se puede utilizar todo, lo que hay y lo que se invente, si sirve como argumento para hacer visible el pensamiento de base» (Richter, 2007: 188). Más allá de esa visualización, el uso y la manipulación de material preexistente es también heredado de la experimentación y la vanguardia- un método eficaz para descontextualizar, tomar distancia y poder así reflexionar sobre los propios registros de la realidad:

«El film ensayo recurre siempre al archivo. Aunque filme directamente de lo real, debe convertir primero estas filmaciones en imágenes de archivo para que puedan ser utilizadas en la reflexión [...] debido a la utilización de imágenes fundamentalmente diversas, puesto que no provienen nunca de un flujo real pre- 
vio, el film-ensayo es paratáxico, es decir, se compone de elementos heterogéneos que no se congregan mediante relaciones sintácticas, sino que en su calidad híbrida fundamentan un proceso de reflexión que es abierto por el hecho de no estar regido precisamente por una sintaxis dada» (Català Domènech, 2014: 209).

Este hecho trae de nuevo a colación el montaje como método determinante en la creación de significados y estímulos de la reflexión (Álvarez y Martín, 12 enero 2015), desvelando, en este caso, una dimensión de las imágenes por encima de su función referencial. De ahí la inevitable relación entre la naturaleza del ensayo y el cine de metraje encontrado o found footage, que en el contexto del discurso ensayístico adquiere el valor equivalente de las citas, poniendo de manifiesto "su condición incompleta en el momento mismo en que pretende completar un nuevo proceso de pensamiento" (Català Domènech, 2014: 353). Los recursos de archivo y el tratamiento que inspira el cine de compilación sobre los contenidos visuales son, simultáneamente, dos herramientas centrales para desarrollar el principio de voluntad estilística expuesto algunos párrafos más adelante.

\subsection{Metalenguaje}

Los recursos disímiles, la manipulación del metraje encontrado y el montaje necesariamente discontinuo son tres de los varios elementos que facilitan la función metalingüística inherente al ensayo. Como parte de una reflexividad integral y relativa al proceso del yo en su experiencia inmediata, el metalenguaje -visible o sugerido- surge como consecuencia lógica de la necesidad de vincular y estudiar los medios del lenguaje y de la técnica empleados en el transcurso y producción de esa reflexión. Recursos acaso más evidenciados, si se quiere, en el medio audiovisual, debido a la captación e inserción automáticas de la información que pueden hacer respectivamente la imagen y el montaje, según se comprueba desde las lecciones magistrales de Liandrat-Guigues, seguidas de las de Orson Welles y Jean-Luc Godard, por citar solo tres leyendas que han dejado obras metalingüísticas especialmente destacadas para la historia ensayística.

Siguiendo exactamente a su homólogo literario, que desvela los elementos de su propia construcción discursiva, el ensayo audiovisual va construyendo las herramientas retóricas al mismo tiempo que el proceso de reflexión, al punto de confundirse ambos ejercicios (Català Domènech, 2005: 133). Esto significa que tras el metalenguaje no hay tanto una razón ética como estructural:
«[...] el film ensayo no es "auto-reflexivo» por un imperativo ético sino porque su propio sistema de funcionamiento, por el que las estrategias empleadas en su construcción pasan a formar parte integrante de su espacio visual y auditivo, hace que el cineasta sea constantemente consciente de los límites estético-ideológicos de su trabajo, que se le aparecen no como horizonte último de su proceder, sino como verdadera plataforma donde se desarrolla. Surge así un nuevo nivel de reflexión superior a la reflexividad [...] en el que quedan inscritas las huellas de aquellas tensiones que el propio trabajo de especulación produce durante su puesta en escena» (Català Domènech, 2014: 353).

Como ocurre con varios de los principios que conciernen directamente a su lenguaje y a su forma, la condición metafílmica del ensayo revela que, pese a centrar el acento en las ideas, fondo y forma permanecen unificados (García Martínez, 2006: 96) en la tarea de reflexionar especialmente sobre y en sus imágenes, sus sonidos y su montaje. Para desentrañar el porqué de las representaciones que va mostrando y explorar con transparencia el flujo de su discurso, el ensayista fílmico aprovecha algunos de los recursos metacinematográficos existentes: autoconsciencia del proceso de producción, aparición en escena de las herramientas creativas, transtextualidad, mezcla de mundos ontológicos, narrador-comentarista, desconexión sonido-imagen, estructura interrumpida, repleta de fracturas, con ocasionales saltos de contexto, obra indeterminada, abierta, no cerrada causalmente.

«Esta enumeración no implica la permanente presencia de todos estos elementos en todo ensayo. Algunos autores optan por utilizar muchos de estos recursos para así trazar películas más destinadas a cuestionar el estatuto de la imagen; sin embargo, otros se adaptan mejor a discursos cercanos a la ficción y, por tanto, se circunscriben a los recursos metafílmicos menos agresivos. En cualquiera de los dos casos, los autores tienen presente que la ruptura del espejo ficcional constituye una de las características propias del género ensayístico» (García Martínez, 2006: 101).

Con las nuevas tecnologías y en particular con la digitalización del proceso audiovisual, el ensayo pareciera volverse cada vez más metalingüístico y heterogéneo. «Hoy se amplifica exponencialmente la cantidad de imágenes preexistentes, registradas y sintéticas, además de textos y toda suerte de efectos sonoros que el videoensayista puede montar en función de las confi- 
guraciones conceptuales que persiga» (Català Domènech, 2019: 53). Más allá del grado de complejidad resultante, lo definitivo es cómo el autor construye con esos materiales brutos e inertes una reflexión rica sobre el mundo (Machado, 2007/2010: 24) y sobre el propio medio que utiliza para representarlo, transformándolos en experiencia de vida y pensamiento.

\subsection{Voluntad de estilo}

En el marco de este estudio se entiende por expresividad un conjunto de fenómenos a la vez elocutivos, inventivos y dispositivos que contribuyen a hacer atractivo un texto ante el lector (Arenas Cruz, 1997: 358). En el macrogénero argumentativo, tal atracción está directamente vinculada a los medios de los que se vale la personalidad del autor para justificar sus pensamientos -al margen de los razonamientosrecurriendo a registros de la lengua común más allá de su función informativa. La voluntad de estilo es, entonces, el personalismo del sujeto en el texto que, tratándose de la clase argumentativa, pasa a tener igual relevancia que el contenido referencial y la información conceptual. De ahí que el estilo, en última instancia, pueda cumplir tres funciones: la estética, la argumental y la persuasiva. «En un texto argumentativo la función del ornatos es una modalidad del pensamiento $y$, secundariamente, de la forma, de tal manera que es la voluntad de estilo la que modela el pensamiento, regula la argumentación y condiciona la persuasión» (Arenas Cruz, 1997: 362).

Lo anterior hace que todas las figuras del lenguaje sean argumentativas debido a su naturaleza persuasiva. Sin embargo, tipos como las metáforas, las metonimias o las hipérboles cumplen a su vez una función cognoscitiva, al indicar que el autor ve la realidad de otra manera y por eso acude al uso figurado del lenguaje (Arenas Cruz, 1997: 365). Particularmente, la metáfora permite al receptor la captación inmediata y la retención de la idea "con más seguridad que si hubiese llegado a ella a través de una secuencia opaca de fórmulas de raciocinio» (Arenas Cruz, 1997: 367). Esto la convierte en una de las figuras que con mayor efectividad funden la función cognoscitiva con la estética y la argumentativa.

«[...] la metáfora es el mecanismo lingüístico-semántico más poético, porque opera una desautomatización inmediata, y, a la vez, el más filosófico, pues ha sido utilizado como instrumento de indagación de la realidad. Esta doble posibilidad reside en la estructura de la metáfora, que permite conocer un objeto mediante las propiedades de otro [...] En el ensayo, sin duda, la metáfora, la analogía, la metonimia, la paradoja y otras figuras de pensamiento aúnan esta doble perspectiva simultáneamente: la afectivo-poética y la cognitivo-argumentativa, de lo que se deriva su efectividad a la hora de orientar la percepción del receptor para que piense por sí mismo lo que se le acaba de mostrar» (Arenas Cruz, 1997: 369).

Analizando más a fondo la naturaleza expresiva del ensayo, encontramos que el principio de forma como estructuración -con sus digresiones, narraciones, interrupciones y demás trozos tejidos al hilo argumental-cumple por sí mismo una función estilística al ser una adecuación del pensamiento. Por su parte, los fragmentos que posibilitan la cualidad flexible, espontánea y abierta de la estructura se transforman a su vez en portadores de figuras que la amplifican o la abrevian: "Si la expresividad tiene una dimensión textual, también tendrá valor artístico la amplitud concedida a cada idea o a cada parte de la exposición en un texto ensayístico, o sea, las técnicas de amplificatio y, las opuestas, de abbreviatio» (Arenas Cruz, 1997: 372). Esto arroja una serie de figuras estético-argumentativas originadas en estos dos niveles, que se agrupan bajo las categorías de adición, clarificación, dilatación y sustitución. Con ellas el autor busca representar mentalmente el objeto o la idea, por lo que algunas tendrán una correspondencia bastante relativa en el lenguaje audiovisual.

Homologar el principio de voluntad de estilo en el ensayo fílmico atraviesa tres opciones básicas. En primer lugar, una herencia del lenguaje literario que le permite utilizar figuras mediante contenidos verbales transmitidos por una voz o por un texto visual, mecanismos que por su parte pueden ser tratados de forma expresiva (suave, familiar, contrastada, rítmica, espontánea, coloquial, redundante, etcétera). En segundo lugar, las derivadas de la estructuración que vienen expuestas en el párrafo anterior. $Y$, en tercer lugar, una herencia del cine experimental que le permite la utilización arbitraria de imágenes y sonidos pasados por un proceso de montaje que puede producir deformaciones, amplificaciones, contrastes, asociaciones y una gran cantidad de opciones que manipulan los materiales audiovisuales al margen de los sistemas lingüísticos basados en lo lineal-narrativo e informativo-representativo, y muy frecuentemente desobedeciendo a estos.

Como ha quedado expuesto en el apartado sobre la forma, este conjunto de probabilidades, en todo caso 
y con independencia de cualquier predominancia, se combina y finalmente organiza en el montaje. Resulta indiscutible -y lo confirmaría una vez más la propia historia del ensayo fílmico- que, por encima de los mecanismos ensayísticos tomados del lenguaje literario, el montaje es el que determina los procesos y los efectos reflexivos, desde la estructura hasta las formas estilísticas. "El montaje es la forma natural que tiene el cine ( $y$, añade Godard, solo el cine) de pensar; y la herramienta que utiliza es la moviola, la mesa de edición en vídeo, o el optical printer, ese artilugio de copiar imágenes que es el instrumento de cabecera de los cineastas del found footage» (Weinrichter, 2007: 31).

Si bien las figuras del lenguaje no parecen haber sido un objeto mencionado especialmente en el ensayo fílmico, en el uso distintivo del material audiovisual más allá de su función informativa (y narrativa) sí se identifican procedimientos que producen el efecto de una representación reflexiva donde se combinan la función estética con la cognoscitiva y la persuasiva (recuérdese, sin ir más lejos, todas las implicaciones estético-ideológicas del montaje rítmico-conceptual de los autores de la Escuela soviética, especialmente Eisenstein y Vertov), siguiendo, por un lado, la naturaleza de los cometidos estilísticos de la argumentación y, por otro, posibilitando la autonomía del ensayo audiovisual respecto a la palabra, es decir, desafiando el logocentrismo al que se le ha intentado someter. ¿Cómo puede una imagen ser argumentativa por sí sola?

«A cámara lenta o congelada, en efecto, una imagen empieza a ser algo más (¿̇o algo menos?) que una imagen: no la miramos en primer grado, sino en cuanto imagen [...] La manipulación del flujo de la imagen es un caso particular del principio de montaje, el otro gran medio que tiene el cine para arrancar de la imagen otro sentido que su contenido literal [...] para hacer ensayo, ya lo decimos, hay que manipular la imagen, tratarla en segundo grado, hay que crear un espacio, una distancia, para volver a mirar. Ello se puede conseguir con la mediación de la voz; pero esa distancia se establece también de forma natural al trabajar con imágenes ajenas [...] el principio del montaje se hace, por fuerza, más efectivo en el remontaje de fragmentos apropiados: al volver a mirar una imagen fuera de contexto se impone una reflexión sobre esa distancia (entre el sentido original y el que adquiere en su nuevo contexto) que puede servir para introducir un componente ensayístico sin necesitar de la voz, como sucede en el ensayo ortodoxo» (Weinrichter, 2007: 30-31).
En este contexto, por lo tanto, resulta aun más imprescindible poner de relieve la importancia de prácticas como la apropiación, el desmontaje o el collage con su equivalencia estético-argumentativa-persuasiva que posibilita, como expresaría el ensayista Harum Faroki, «imágenes dialécticas» surgidas de la absorción de otros textos y de la relectura de las trazas inscritas en ellos (Weinrichter, 2007: 30). Aunque las nominaciones de estos recursos son más relativas a unos subgéneros, métodos o técnicas que ante todo privilegian y exploran -muy por encima de la palabra- la potencialidad dialéctica y expresiva del montaje como centro exclusivo del lenguaje audiovisual, la descripción de su procedimiento permite su homologación al de las figuras literarias, incluyendo por supuesto sus efectos en función del pensamiento: la estructuración de film-ensayo en el montaje apunta a hacer nuevas relaciones significantes entre sus materiales; reposa sobre cotejos, superposiciones y desplazamientos; opera por comparación y puesta en resonancia; así revela, dentro de un proceso de ruptura y derivación, un pensamiento en acto (Moure, 2004: 37).

La correspondencia más frecuente y evidente respecto a figuras estilísticas entre el ensayo literario y el audiovisual es la metáfora, que puede generarse en la asociación de planos o en las relaciones sonoro-visuales, de las que también es factible que se desprendan contrapuntos, símbolos, ironías y paradojas, por citar lo más conocido. Esto demuestra el resultado de que los vínculos entre imágenes y sonidos no se rijan por una lógica narrativa ni ilustrativa. Al colisionar las imágenes entre sí y sobre todo estas con los sonidos, se producen fracturas que "sirven como medio para instalar la duda o para doblar la mirada hacia sí mismo» (Blümlinger, 2007: 62), en una especie de autorreflexión metalingüística (lo segundo), propiedad ensayística por excelencia y otra gran contribución de la no-linealidad o discontinuidad que «provoca una mayor visibilidad del mecanismo del montaje y hace al espectador consciente de las costuras y las nuevas relaciones significantes que la unión de materiales diversos genera», lo que a su vez favorece el predominio de la metáfora, la analogía o la asociación reticular (Blümlinger, 2007: 62).

Una de las observaciones más interesantes y beneficiosas de la autora citada (y de Liandrat-Guigues) se refiere al intersticio -evidenciado por la constitución discontinua del montaje ensayístico-, no tanto como un nido de figuras lingüísticas sino como un desencadenante de reflexión, "un entre dos que coloca al 
pensamiento en el interior de la imagen » (Blümlinger, 2007: 62). En ese espacio vacío es posible el cuestionamiento radical de la imagen [...] En este intersticio el espectador puede crear polos de reflexión o de tranquilidad. "Posibilita una lectura oscilante que se mueve entre la imagen y el lenguaje, el presente y el pasado, entre una dimensión espacial de la fotografía y una temporal del comentario referido a lo pasado [...]» (Blümlinger, 2007: 62).

De esta manera, los mecanismos y los efectos reflexivos a que da lugar el montaje terminan de cumplir el mismo papel polivalente que el ensayo literario le asigna a sus figuras retóricas, integrando de igual modo la estimulación de la emoción estética que transforma la voluntad estilística en la propiedad más certera a la hora de transmitir el flujo-pensamiento de un yo a un tú a través de la emoción y la razón a partes iguales, para compartir y persuadir de la necesidad de pensar acerca de los problemas que se le plantean.

\subsection{Mecanismos dialógicos}

Como consecuencia de todas las propiedades emanadas de la subjetividad, el lector o espectador de un ensayo está llamado a ser motivado e interactuar con el texto ensayístico para complementarlo y darle así su sentido final, estableciendo un puente entre el autor y el espacio social. Literario o fílmico, el ensayo ofrece la forma de una reflexión en el transcurso de conversar con la realidad. Pero "para completar su funcionamiento, precisa de la colaboración de la mirada del espectador, que éste renuncie a su proverbial distancia y se integre en el dispositivo, no para abandonarse a la inconsciencia, sino para completar[lo] con su conciencia [...]» (Català Domènech, 2005: 126).

Por esta razón el diálogo ensayístico sugiere precisamente eso: un diálogo donde los participantes son libres de comunicar, pensar, interpretar y opinar. Este hecho significa que la persuasión que le corresponde en su cualidad argumentativa no es más importante que la vocación reflexiva que tan sinceramente el ensayista busca compartir con su receptor sin ánimo de convertirse en autoridad. Ese pacto se puede resumir de la siguiente manera: "Yo, el autor, estoy reflexionando sobre un problema, y comparto mis pensamientos contigo, el espectador» (Rascaroli, 2009: 15). A diferencia de la relación que se produce con los géneros informativos, en el ensayo el espectador es instado a acompañar la experiencia del director o de su línea de razonamiento «de igual a igual como un socio en la comunicación» (Rascaroli, 2009: 15). El objetivo de este intercambio dialógico es motivar la conciencia, es decir, «alterar de alguna manera nuestro sistema de creencias o de conocimientos, pero al margen de toda intención pedagógica o edificante» (Arenas Cruz, 1997: 435). Desde este marco interpretativo, la finalidad del ensayo se puede entender como:

«[...] La propuesta, por parte del autor, de un sistema de valores (docere) a través de procedimientos de expresividad verbal elocutiva y macroestructural dispositiva que determinan a la vez su pensamiento (delectare); en el ámbito de estimaciones, el lector es libre de aceptar, rechazar o quedar indiferente ante dicha propuesta porque el único garante de la misma es la palabra del autor, parcial y subjetiva» (Arenas Cruz, 1997: 436).

Tal descripción ayuda a identificar una correspondencia superlativa entre el ensayo literario y el audiovisual respecto a los medios con los que ambos hacen efectiva la actividad dialógica buscando despertar la capacidad reflexiva del receptor, desde el lenguaje verbal con apelaciones directas del autor en segunda persona, pasando por las figuras dialécticas que demandan la participación receptiva y, por encima de todos estos medios, muy especialmente la apertura formal/estructural. En el diálogo implícito con el director, el espectador toma cuerpo por medio de diferentes elementos: «se trata de un receptor modelo al que se le invoca en la voz en off con el deíctico 'tú' $y$ verbos en segunda persona, o que queda envuelto en la nebulosa del 'nosotros' y los pronombres indefinidos que emplea el autor mediante la voz en off " (García Martínez, 2006: 103).

La estructura misma como instrumento de interpelación se explica por la dinámica que se genera con la disposición de continuos interrogantes que el transcurso reflexivo del autor deja abiertos para que el receptor, singularizado, participe en la construcción del pensamiento:

«[...] the enunciator addresses the spectator directly, and attempts to establish a dialogue. The 'I' of the essay film always clearly and strongly implicates a 'you' - and, for me, this is a key aspect of the deep structures of the form. 'You' is called upon to participate and share the enunciator's reflections. It is important to understand that this 'you' is not a generic audience, but an embodied spectator. The essay film constructs such a spectatorial position by adopting a certain rhetorical structure: rather than answering all the questions that it raises, and delivering a 
complete, 'closed' argument, the essay's rhetoric is such that it opens up problems, and interrogates the spectator; instead of guiding her through emotional and intellectual responses, the essay urges her to engage individually with the film, and reflect on the same subject matter the author is musing about. This structure accounts for the 'openness' of the essay film» (Rascaroli, 2009: 34).

Tres condiciones son la base del efecto de apertura que sirve para estimular la mente del receptor de ensayos y lo invitan a completar o prolongar el texto para sí (Arenas Cruz, 1997: 439). En primer lugar, la falta de exhaustividad con la que se tratan los temas (que abre la posibilidad al receptor para complementarlos por su cuenta). Lo mismo ocurre, en segundo lugar, con la ausencia de síntesis, recapitulaciones o conclusiones de lo dicho. Y, en tercer lugar, la heterogeneidad respecto al todo, que de modo permanente reenvía a un 'fuera de texto' y, por otra parte, presenta una organización y distribución cuya libertad a la hora de producir los enunciados exige la complicidad del receptor:

«El aparente desorden en que se suceden [los fragmentos] implica disponibilidad, fecundidad, germen, apertura a un mundo de posibles significaciones que el receptor puede activar en su lectura [...] Así, las citas, sentencias, pequeñas narraciones, fragmentos de pensamientos, ejemplos, etc., aunque no despliegan todas sus posibilidades explícitamente en el ensayo donde aparecen, siguen trabajando subterráneamente en la mente del lector. Esta apertura sintáctico-semántica conlleva, por tanto, una estrategia de lectura que, si bien no creemos que se apoye en la admisión de cualquier interpretación potencial o posible, al menos puede conducir en determinados casos al desarrollo de ciertas lecturas imprevistas por el autor» (Arenas Cruz, 1997: 439-440).

La propiedad dialógica del ensayo -y su necesidad intrínseca de provocar permanentemente la participación del receptor- pueden interpretarse como el efecto de una "subjetividad sin resolver» (Corrigan, 2011: 55). En su expresividad desatada, el yo no solo queda expuesto en el espacio compartido de la forma, sino que además la respuesta a la apertura que esta conlleva ya es parte del tú. Se concluye entonces que los alcances de la interacción dialógica trascienden al autor, al término de convertirlo en el otro. Aunque resulte paradójico, cuanto más inmerso esté el yo en sí mismo y se exprese desde ahí, más dispersa se revelará su forma y, en consecuencia, más par- ticipación e implicación demandará del tú. Es decir, más será el tú.

Entendiendo cabalmente el sentido del subjetivismo, el ensayo es una forma de expresión subjetiva que habita y reformula constantemente las expresiones del otro, refiriéndose entonces a una estructura donde la subjetividad ensaya diferentes posiciones dentro del mundo como forma de probar diferentes yoes (Corrigan, 2011: 31). El principio dialógico es, como consecuencia, el eslabón entre el sujeto y la intervención social que por su naturaleza recae en toda obra ensayística.

\subsection{Intervención sociopolítica}

El principio de intervención social, que por derivación es político, empieza en la misma naturaleza subjetivo-reflexiva del ensayo y tiende su puente práctico desde el yo hasta la esfera pública mediante todas las manifestaciones de apertura que le son propias. "Al transmitirse la representación de la realidad social a través de la subjetividad, esta se convierte en su expresión» (Blümlinger, 2007: 55). Y es precisamente por la extensión de la experiencia individual «por lo que el ensayo puede ser un método de conocimiento y un cauce de comunicación adecuado para meditar acerca de la condición humana y acerca del medio sociocultural en que el ensayista está inmerso» (Arenas Cruz, 1997: 385).

Pero esta es solo la raíz de una capacidad extraordinaria del ensayo como experiencia para transmutar no solo al sujeto mediante su propio replanteamiento y reconstrucción a lo largo y ancho de la expresión, sino además y sobre todo, su poder para transformar la percepción y las formas de pensamiento sobre la realidad. De suerte que la función social se mide también «por el influjo que una visión problemática y personal de un individuo ante su mundo haya podido ejercer en el funcionamiento o comprensión general de una sociedad» (Arenas Cruz, 1997: 440).

$Y$ puesto que el ensayo es ante todo un acto que manifiesta el espíritu crítico del ser humano (Bense, 1947), el ensayista suele estar abierto a la vida de su momento histórico (Arenas Cruz, 1997: 441), razón por la cual la trayectoria histórica del ensayo, literario y fílmico, confirma reiteradamente sus vínculos especiales con épocas igualmente críticas, donde «el saber constituido, la ciencia oficial, está bloqueado, encontrándose incapaz de integrar en una visión integral nuevas relaciones (hechos, situaciones, sensaciones)», según López Campillo (1971: 445). 
«[...] lo peculiar de los ensayistas es que están al margen de sistemas organizados, intentan expresar algo nuevo, que no pueden decir las ideologías del momento, porque precisamente ellas excluyen ese algo de entrada. Son escritores de un momento de crisis quienes, en vez de pensar superar la crisis aplicando las recetas de un dogma (...) procuran definir espontáneamente el objeto y expresarlo con métodos adecuados a cada caso [...] Esta posibilidad que encierra el ensayo de modificar la realidad, o al menos de intentarlo, responde a la nueva manera en que el humanista y su pensamiento se sitúan en el mundo: el ensayo permite expresar, frente a otras clases de textos argumentativos, la imposibilidad de dar una forma precisa o una respuesta a determinadas cuestiones de la vida o de la cultura: en el ámbito de las sociedades democráticas plurales sólo es posible expresar opiniones subjetivas, convicciones personales, por tanto, cuajadas en función de un aquí y un ahora anejos a la propia situación existencial» (Arenas Cruz, 1997: 442-443).

Esta intervención transformadora se hace aun más imprescindible cuando se trata de reconstruir y reflexionar sobre los traumas históricos, al punto de que sobran señales para reconocer, por ejemplo, cómo los mecanismos fundamentales del ensayo fílmico (subjetividad y experimentación) avanzaron repentina y vigorosamente bajo los efectos de la II Guerra Mundial.

Nadie pone en duda la dinámica transformadora ni discute la dimensión política que acarrea el que la experiencia individual se manifieste, se comparta y finalmente se desdoble en un espacio público frente a los sistemas de representación instituidos en cualquier campo, y en mayor medida cuando las depresiones históricas y sociales lo demandan. Por eso la historia del siglo XX confirma muy especialmente que el fracaso, la crisis y el trauma son experiencias-fuente del ensayo, a cuyo ejercicio han terminado sumándose también ciertos márgenes sociales que, sin ser deliberadamente militantes, cumplen el papel de representar la pluralidad social en su compleja cotidianidad.

«In this sense, the essayistic almost invariably practices, regardless of the subject matter, a distinctive form of politics, a politics quite different from the ideological and political strategies of narrative fiction films or conventional documentaries. In essay films, the subversion of a coherent subjectivity within the public experience of the everyday may not always be an easily decipherable and clear politics but is, perhaps always, a politics whose core is ideological instability» (Corrigan, 2011: 33).
Con esto terminaría de destacarse la trascendencia del ensayo como vehículo para la construcción de una democracia comunicativa fidedigna, «en la que el hombre debe alcanzar, superando la seducción de la opinión uniformadora que transmiten los medios de comunicación de masas, su mayor reconocimiento como individuo y como ciudadano» (Arenas Cruz, 1997: 445). Se trata, por tanto, de una ética sustancial a partir de la que el acto ensayístico lleva de la libertad personal a la libertad social: «El pensamiento individual se visualiza y se expande víricamente, transmutando las coordenadas tecnológicas e industriales que lo hacen involuntariamente posible. El receptor de los ensayos, por su parte, se ve literalmente obligado a revisar el mundo ante la representación excéntrica pero razonada que de este le ofrecen los ensayistas» (Català Domènech, 2014: 550).

Por todo lo anterior -e inspirándonos en varias de las consideraciones de este último autor a lo largo del texto citado-, es posible llegar a la conclusión de que la reflexión ensayística, como compendio de lenguaje, conocimiento y tecnología, produce un enriquecimiento poético del mundo. Se trata de una manifestación que no solo aglutina distintas experiencias de la evolución genérica y tecnológica del universo audiovisual; también, y esto es lo más importante: como en el Renacimiento, ocupa el lugar de una gran respuesta, acaso la más satisfactoria, frente al derrumbamiento de los valores mediáticos en el caos de una posmodernidad deshumanizadora donde cobra valor especial la reflexión y la representación de la Historia a través de cada verdad individual.

\section{CONCLUSIONES}

Como acto que conjunta la manifestación racional y emocional del ser humano, el ensayo audiovisual es una continuación del literario más que un equivalente de principios que, por otra parte, son constantes, indisolubles, difícilmente jerarquizables. No obstante, propiedades como el metalenguaje o la misma asistematicidad pueden no revelarse de modo frecuente a pesar de relacionarse con la subjetividad y con el proceso de hacerse la obra.

A diferencia de lo que sucede con aspectos más estructurales e ideológicos, las aproximaciones teóricas sobre el ensayo audiovisual -todavía en sus albores, como es de entender si se comparan con las de la teoría literaria- no parecen contemplar especialmente las figuras del lenguaje ni enfatizar conceptos que se correspondan con la voluntad de estilo definida entre 
las bases de su homólogo literario. Sin embargo, lo mismo que ocurre con la manifestación del yo/autor/ enunciador, traducir el principio de voluntad de estilo en el ensayo audiovisual puede pasar por uno o más recursos -simultáneos o puntuales- adoptados del lenguaje literario o registrados en la imagen y procesados en el mecanismo del montaje.

Aunque las nuevas tecnologías ponen en alza la manifestación de la subjetividad, faltan estudios orientados hacia la incidencia de estas sobre la construcción del texto ensayístico propiamente dicho y los efectos sociales como resultado de su particularidad dialógica. A la par con este vacío, las referencias canónicas para analizar las correspondencias entre ambos campos no parecen contar con el estudio de cinematografías periféricas ni profundizar en prácticas experimentales que dieran respuesta a lo anterior.

La complejidad y efectos potenciales del ensayo audiovisual invitan a ensanchar investigaciones por lo menos en dos sentidos. El primero es relativo a las variaciones o transformaciones en su lenguaje al filtrar y ser filtrado por las nuevas tecnologías y muy especialmente respecto a las opciones que puedan surgir de la interactividad, hecho que tal vez produ- ciría una estructura formal mucho más abierta y por lo tanto más estimulante para la participación del receptor. El segundo punto de búsqueda correspondería a la repercusión personal y al impacto social más allá de la distribución de la obra ensayística en sus correspondientes mercados: si a partir de la conciencia individual el ensayo es un medio transformador en términos sociopolíticos, ¿cómo exactamente se produce esa modificación tanto en el sujeto como en los entornos hasta donde llega? Este podría ser un eslabón muy necesario para interconectar el estudio del ensayo audiovisual con unas derivaciones psicosociales y antropológicas que explicarían por qué, desde Montaigne, la práctica ensayística ha ido expandiéndose, inexorable, con la adopción de toda suerte de lenguajes y de técnicas, para trascender los géneros y las representaciones institucionalizadas.

\section{AGRADECIMIENTOS}

Este artículo se inscribe en el marco del proyecto de investigación titulado «El ensayo en el audiovisual español contemporáneo» (Ref. CSO2015-66749-P), financiado por el Ministerio de Economía y Competitividad y el Fondo Europeo de Desarrollo Regional.

\section{REFERENCIAS}

Adorno, Theodor (1962). El ensayo como forma. En Theodor Adorno. Notas de Literatura. Madrid: Ariel, pp. 13-35.

Álvarez, Cristina y Martín, Adrián (12 enero 2015). Entender el montaje en el ensayo audiovisual. Disponible en: http:// cinentransit.com/entender-el-montaje-en-el-ensayo-audiovisual/. [Fecha de consulta: 1 noviembre 2020].

Arenas Cruz, María Elena (1997). Hacia una teoría general del ensayo. Construcción del texto ensayístico. Cuenca: Ediciones de la Universidad de CastiIla-La Mancha.

Bense, Max (1947). Über den Essay und seine Prosa. En Merkur, 1, pp. 414424. Disponible en español en: https:// lecturayescrituraunrn.files.wordpress. com/2013/08/bense-max-sobre-el-ensayo-y-su-prosa.pdf [Fecha de consulta: 1 noviembre 2020].

Bergala, Alain (2000). Qu'est-ce qu'un film-essai? En Sylvie Astruc (ed.). Le film-essai, identification d'un genre. París: Bibliothèque Centre Pompidou.
Blümlinger, Christa (2007). Leer entre las imágenes. En Antonio Weinrichter. (ed.). La forma que piensa. Tentativas en torno al cine-ensayo. Pamplona: Fondo de Publicaciones del Gobierno de Navarra, pp. 50-63.

Català Domènech, Josep M. (2005). Film-ensayo y vanguardia. En Josetxo Cerdán de los Arcos y Casimiro Torreiro (coords.). Documental y vanguardia. Madrid: Cátedra, pp. 109-158.

Català Domènech, Josep M. (2014). Estética del ensayo: La forma ensayo, de Montaigne a Godard. Valencia: Universitat de València.

Català Domènech, Josep M. (2019). Pensar el cine de pensamiento. Ensayos audiovisuales, forma de una razón compleja. En Norberto Mínguez (ed.). Itinerarios y formas del ensayo audiovisual. Madrid: Gedisa, pp.13-59.

Corrigan, Timothy (2011). The Essay Film. From Montaigne, after Marker. Oxford Universiy Press.

Cruz Carvajal, Isleny (2019). Aspectos ensayísticos de la falsedad documental. Estudio de Un tigre de papel. Comunicación y Medios, 28 (39): 80-96. Disponible en https://comunicacionymedios.uchile. cl/index.php/RCM/article/view/52927. [Fecha de consulta: 1 noviembre 2020].

García Martínez, Alberto Nahum (2006). La imagen que piensa. Hacia una definición del ensayo audiovisual. Comunicación y Sociedad, 19 (2): 75-106. Disponible en https://revistas.unav.edu/ index.php/communication-and-society/article/view/36306/30761. [Fecha de consulta: 1 noviembre 2020].

García Roldán, Ángel (2020). El vídeo-ensayo en las metodologías artísticas de investigación en educación. Comunicación y Métodos, 2 (1): 108-125. [Fecha de consulta: 1 noviembre 2020]. https://doi.org/10.35951/v2i1.68.

Liandrat-Guigues, Suzanne (2004). Un art de l'equilibre. En Suzanne Liandrat-Guigues y Murielle Gagnebin (dirs.). L'Essai et le cinema. Seyssel: Champ Vallon, pp. 7-12.

Liandrat-Guigues, Suzanne (2008). Una historia invisible. Archivos de la Filmoteca, 57-58 (I), pp. 102-115.

Lopate, Phillip (1996). In Search of the Centaur: The Essay-Film. En Charles 
Warren. Beyond Document. Essays on Nonfiction Film. Middletown: Wesleyan University Press, pp. 243-270.

López Campillo, Evelyne (1971). Apuntes sobre una evolución en la temática del ensayo español (1895-1930). Cuadernos Hispanoamericanos, 255: 445-460. Disponible en http://www.cervantesvirtual.com/nd/ark:/59851/bmct44b4. [Fecha de consulta: 1 noviembre 2020].

Lukács, Georg (1910/2006). Sobre la esencia y la forma del ensayo. Una carta a Leo Popper (1910). Anuario de Letras Modernas, 13: 225-242. Disponible en: http://www.journals.unam. $\mathrm{mx} /$ index.php/al_modernas/article/ view/31063. [Fecha de consulta: 1 noviembre 2020]. https://doi.org/10.22201/ ffyl.01860526p.2006.13.714
Machado, Arlindo (2007/2010). El film-ensayo. La Fuga, 11. Disponible en http:// lafuga.cl/preview_articulo/409. [Fecha de consulta: 1 noviembre 2020]

Mínguez, Norberto (ed.). (2019). Itinerarios y formas del ensayo audiovisual. Madrid: Gedisa.

Montero, David (2006). La herencia de Montaigne. Trayectos posibles para una caracterización del ensayo cinematográfico. Revista Mostra Internacional de Cinema Europeu Contemporani. Disponible en http://www.ocec.eu/pdf/2006/ montero_david.pdf [Fecha de consulta: 17 agosto 2021].

Moure, José (2004). Essai de définition de l'essai au cinema. En Suzanne Liandrat-Guigues y Murielle Gagnebin (dirs.).
L'Essai et le cinema. Seyssel: Champ Vallon, pp. 25-39.

Rascaroli, Laura (2009). The Personal Camera. Subjective Cinema and The Essay Film. Columbia: Wallflower Press.

Richter, Hans (2007). El ensayo fílmico, una nueva forma de la película documental. En Antonio Weinrichter. (ed.). La forma que piensa. Tentativas en torno al cine-ensayo. Pamplona: Fondo de Publicaciones del Gobierno de Navarra, pp. 186-189.

Weinrichter, Antonio (2007). Un concepto fugitivo. Notas sobre el film-ensayo. En Antonio Weinrichter. (ed.). La forma que piensa. Tentativas en torno al cine-ensayo. Pamplona: Fondo de Publicaciones del Gobierno de Navarra, pp. 18-48. 